\title{
Impact of lockdown due to COVID-19 on the dietary habits of youngsters of Delhi-NCR
}

\author{
Arora D. ${ }^{1 *}$, Narang S. ${ }^{2}$ \\ DOI: https://doi.org/10.17511/ijphr.2021.i03.01
}

1* Devesh Arora, Research Division, ECON C\&R, New Delhi, India.

2 Shaurya Narang, Research Division, ECON C\&R, New Delhi, India.

With over a year after the first coronavirus case reached Delhi, the total number of infections and deaths has reached a sky-high mark. The response of the Delhi government involved the imposition of multiple lockdowns. This decision, though slowed down the positivity rate, had unprecedented effects on the dietary habits of young individuals in the city. Forced to stay at home due to the lockdown, these individuals engaged in unhealthy daily routines and dietary habits. With the close link between diet and immunity it becomes imperative to collect data in this regard. The present paper records the dietary habits of individuals in the city using a web-based survey. The findings are presented and analyzed graphically. It was observed that the lockdown harmed the dietary habits of young individuals. A decrease in the level of exercise, water intake and increase in weight were the major variables leading to this conclusion.

Keywords: COVID-19, Dietary Habits, Lockdown, Physical Fitness

Corresponding Author

Devesh Arora, Research Division, ECON C\&R, New Delhi, India.

Email: aroradevesh0209@gmail.com
How to Cite this Article

To Browse

Arora D, Narang S. Impact of lockdown due to COVID-19 on the dietary habits of youngsters of Delhi-NCR. Public Health Rev Int J Public Health Res. 2021;8(3):32-38.

Available From

https://publichealth.medresearch.in/index.php/ijphr/ article/view/157

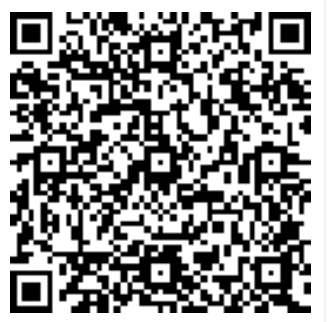

Manuscript Received 2021-05-22

Conflict of Interest No

Review Round $\mathbf{1}$
2021-05-30
Funding
Nil

Review Round 1 $\mathrm{Nil}$

$\begin{gathered}\text { Review Round } 2 \\ \text { 2021-06-05 }\end{gathered}$
Ethical Approval
Yes

Review Round 3 2021-06-11

Accepted 2021-06-13

Plagiarism X-checker $6 \%$ 


\section{Introduction}

The COVID-19 pandemic has taken the world by storm. Originally thought to have originated in China, it has made its traces onto the rest of the world and has mutated along the way. With over 24 million affected people and more than 20 million recovered, India has been one of the worst-hit countries in the world [1]. Nations have tried a variety of different moves to counter the pandemic with one of them being the countrywide lockdown. In the course of the last eighteen months, India has gone through several lockdowns. These attempts, although delay the spread of the virus, have caused negative impacts on the life of an individual. The youth of the nation has been reduced to a much more sedentary lifestyle. With reduced exercise and academic/work obligations, they find themselves in anxiety-inducing positions [2]. This anxiety induced by the lockdowns has impacted the circadian rhythms of these individuals and has caused them to make unsound dietary decisions.

For several decades, scientists and medical experts have increasingly focused on the regulation of diet as an instrument to prevent and combat several illnesses. Maintenance of healthy dietary habits along with other factors leads to maximization of physical as well as mental wellbeing [3]. In the wake of the COVID-19 pandemic, this discussion becomes even more important. Researchers have already established closed links between dietary habits and immunity [4]. While existing literature examines dietary patterns in various age groups across the globe[5,6,7], there's a lack of literature that is specific in terms of age group, income levels and region. Towards this, the present study aims to assess the magnitude of the impact a lockdown has on the dietary habits of the middle class and richer class youth in times of lockdown in the Delhi-NCR region.

Objective: This survey research was conducted to record the dietary and exercise habits of middleclass youngsters in Delhi-NCR during the period of lockdown to run a comparison with pre-pandemic times.

\section{Methodology}

Study Method: Online questionnaire

Sampling Technique: Simple random sampling
Inclusion Criteria: Only responses from respondents aged between $16-27$ residing in the Delhi NCR region were considered.

Ethical Compliance: All participants were well informed about the objective of the study and the intent to publish it in a journal.

Statistical Analysis: Spearman Correlation Test was performed to determine the correlation between discrete variables. The Shapiro-Wilk test was also performed to evaluate the distribution of variables. All the variables had a skewed distribution.

\section{Result}

A total of 110 participants between the age group of 16 and 26 took part in this study through an online questionnaire.

Figure 1: Income of Participants

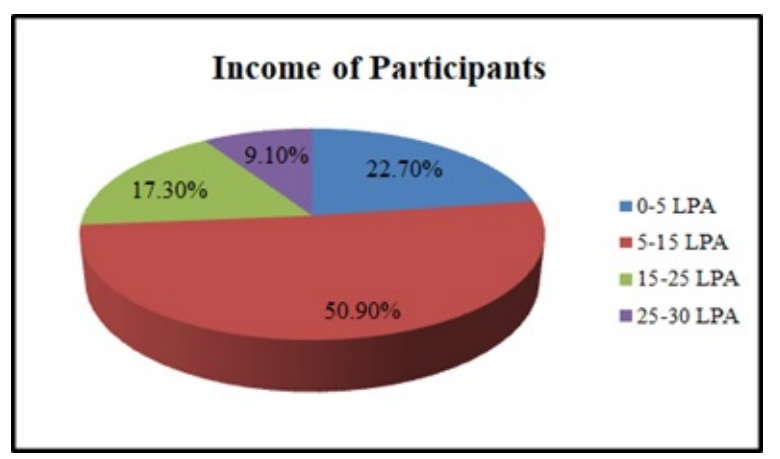

Figure 1: presents information about the income level of participants. The majority of the population chosen lies in the income bracket of the middle class and the rich which is the primary target audience of this study.

\section{Water Intake}

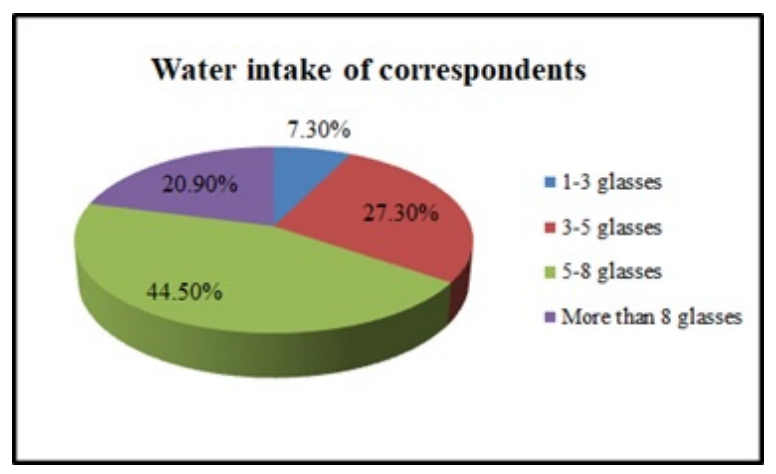

Figure-2: Water Intake statistic

Survey size: 110 participants 
Figure 2: is a presentation of the recorded water intake of participants. It was observed that most participants have poor and deprived water intake per day. $7.30 \%$ and $27.30 \%$ of participants take $1-3$ and 3-5 glasses per day respectively. About $44.5 \%$ of participants consume 5-8 glasses of water per day making their intake relatively better even though it fell short of the recommended 10 glasses per day. [8]

\section{Specific food intake}

Data was collected regarding the consumption of different types of food and the impact that the lockdown had on their consumption. Food consumption was divided into 6 major categories namely: Cereals, Fresh fruits and vegetables, Legumes, Meat and non-veg, Dairy products and Processed Foods. The following changes were noted:

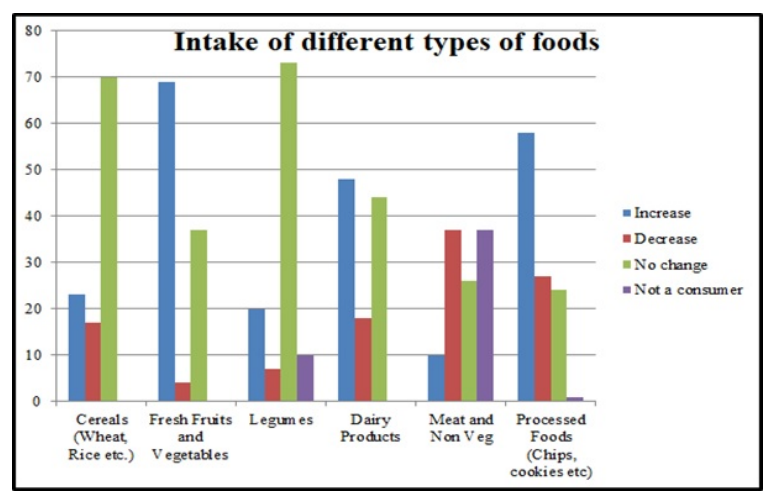

Figure 3: Eating patterns of different types of foods

\section{Skipping Meals}

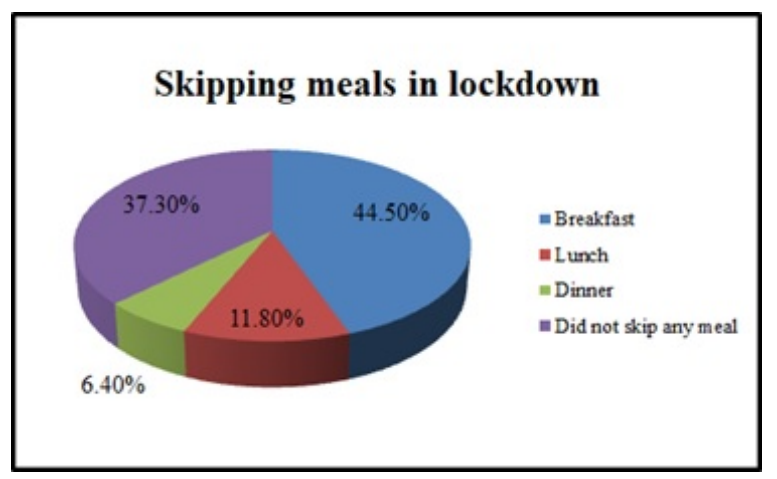

\section{Figure 4: Meal skipping patterns during lockdown}

The study recorded meal skipping patterns of the survey participants. It was observed that around $44.50 \%$ of participants skipped breakfast during the lockdown.
While only $6.40 \%$ of participants skipped dinner, a big proportion adhered to the standard three meal system $(37.30 \%)$.

\section{Workout Levels}

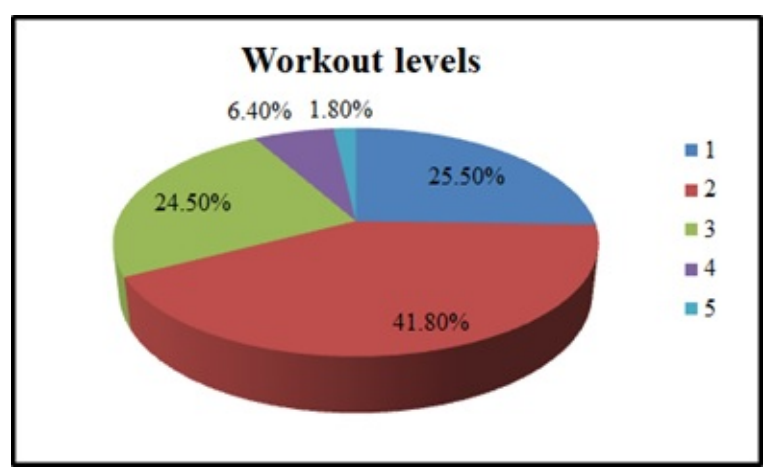

Figure 5: Exercise levels during the lockdown.

\section{Scale Guidelines}

01 . No workout at all

02. Mild workout; daily or seldom walking/cardio for less than 30 minutes

03. Normal workout; fairly regular in training that included at least 1 hour of exercise

04. Hard workout; exercise for 1-2 hours regularly that includes cardio, core and simple weight training

05. Extreme workout; exercise for around 2-3 hours regularly that included callisthenics and intense weight training apart from normal cardio.

This study reported that a majority resorted to mild or no workout during the lockdown period (41.80\%no workout and $25.5 \%$ - mild workout as per figure). Only $8.40 \%$ of the study group engaged in a rigorous workout. The need for boosting immunity and staying fit was not taken seriously by this age group. Lacking workouts is closely related to an increase in weight as well, making the individuals more vulnerable to COVID-19.

\section{Change in Weight}

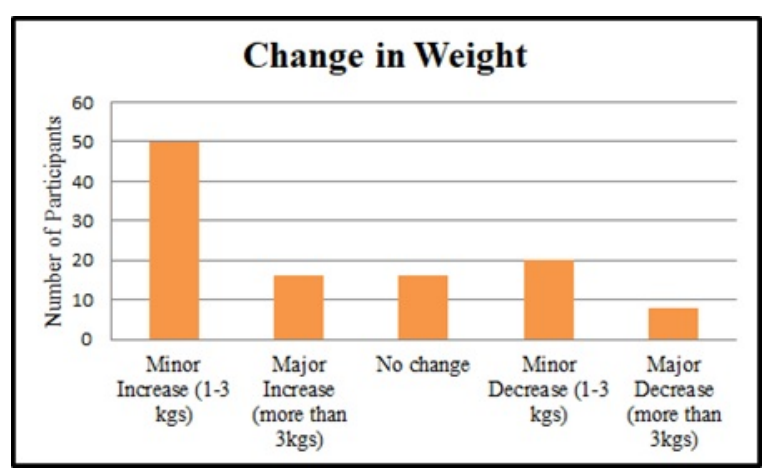




\section{Figure 6: Change in weight}

Figure 6 presents data on weight change patterns of the correspondents. Weight change was divided into five categories as can be seen in the figure. 50 participants $(45.5 \%)$ reported an increase in their weight in lockdown. $14.5 \%$ of participants experienced a major increase in weight by more than $3 \mathrm{kgs}$. It is only a small proportion (7.3\%) that witnessed a major decrease in weight by more than 3 kgs.

\section{Overall diet}

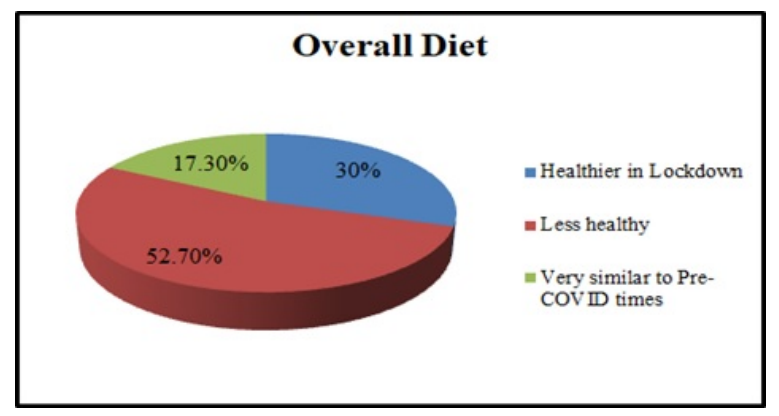

\section{Figure 7: Overall diet during lockdown}

The survey also questioned the participants about their perception of their dietary habits during the lockdown. A majority of $52.7 \%$ of participants admitted that their overall diet was less healthy as compared to pre-pandemic times while 30\% felt that their diet habits improved. $17.3 \%$ noted that there was no noticeable change in their dietary habits.

\section{Discussion}

Water Intake Just $20.9 \%$ of participants kept themselves hydrated by drinking more than 10 glasses per day. According to the National Centre for Biotechnology Information, in the USA, less than the recommended amount of water intake is concerned with an increase in constipation, impaired cognitive process, disruption in mood and development of headache. [9].

\section{Specific Food Items}

01. Cereals: The lockdown had little to no impact on the consumption of cereals for the majority of participants. 23 of the participants reported an increase while around 17 reduced their consumption of the same. Cereals are a staple in most households and hence they saw very less variability even during the lockdown.
02. Fresh Fruits and Vegetables: Fresh fruits and vegetables on the other hand saw an increase in consumption as 69 participants reported an increase in their consumption while 4 reported a decrease and 37 reported no change. This was the only scenario where the lockdown caused a positive dietary habit change.

03. Legumes: Legume consumption was also relatively less affected with more than 70 participants reporting no change in their legume consumption during the lockdown. Due to easy availability and storage, households maintained consumption of legumes with some even increasing their consumption. A small minority of participants opted for a decrease in legume consumption (7 participants).

04. Meat and Non-Veg: Consumption of meat and non-veg were the most hit due to imposition of the lockdown. It saw the highest decrease with up to 37 participants reporting a decrease in its consumption. It is important to note that up to 35 participants were vegetarian consumers and hence 37 people reporting a decrease amounts to a $50 \%$ drop in meat consumption due to the lockdown. 10 participants reported an increase while 26 participants maintained their consumption. This decrease happened due to fears of coronavirus infection in obtaining and consuming the meat leading households to cut their consumption

05. Dairy Products: The survey showed an increase in dairy consumption as up to 48 participants reported an increase in their dairy intake. 42 participants maintained their consumption while 18 participants reduced it. Coronavirus fears did not grip the dairy industry as tightly as the meat industry was gripped. As a result people found an alternative source of protein in dairy and increased its consumption.

06. Processed Foods: The lockdown saw a massive increase in processed food consumption with 58 participants reporting an increase. 27 and 24 participants reported a decrease and no change respectively. Processed foods are high in caloric value as well as sugars which indicate low nutritional value.

\section{Skipping Meals}

Skipping meals is a key variable to observe in the case of youngsters as many individuals of this age group tend to skip meals because of erratic lifestyle patterns. 
Skipping breakfast has been observed as the most common cause with $44.5 \%$ of correspondents not eating breakfast on average. The relevance of skipping meals and its effect on the health of young individuals has already been established by researchers.

"Daily breakfast consumption is associated with less overweight and obesity and with healthier dietaryand physical activity-related behaviours among urban Indian students." [10]. This becomes another indication of the poor dietary habits of the youth during the lockdown. Skipping breakfast is usually concerned with low immunity, lethargy and a greater risk of heart diseases.

\section{Workout Levels}

Exercising in Lockdown was hard as captivity of houses could not provide ample room for exercise. Restricted access to sports facilities and gymnasiums further aggravated the problem as people were forced to find new methods of staying fit indoors. As a result, unavailability of equipment and closure of public parks and facilities resulted in people shifting to a much more sedentary lifestyle.

\section{Change in Weight}

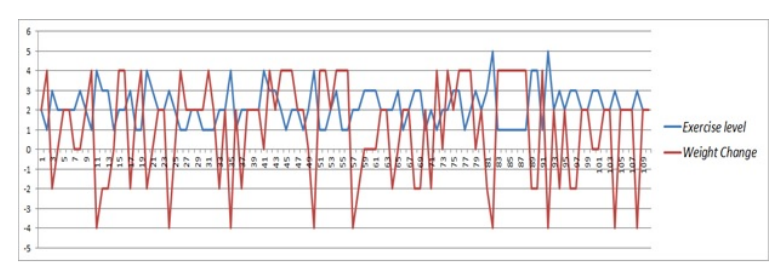

\section{Figure 8: Correlation between Exercise Level and Weight Change}

Weight is one of the most widely accepted indicators of overall health in youth. Putting on weight due to poor eating habits or low exercise levels is a topic of worry for an individual. It has been observed that obese and overweight people are at high risk for COVID-19 and can develop secondary complications.[11]. It was observed that around $45 \%$ of participants recorded an increase in weight by 1-3 kilograms. The Spearman correlation test was conducted by assigning specific numbers to weight patterns to convert them to discrete variables. Values of $+4,+2,0,-2$ and 4 were assigned to Major Increase $(3+\mathrm{kg})$, Minor Increase (1-3 kg), No Change, Minor Decrease (1-3 kg) and Major Decrease $(3+\mathrm{kg})$ respectively. The Spearman test revealed a strong correlation of (-) 0.72 between weight change and exercise.
Participants who followed rigorous exercise schedules showed a major decrease in weight which is indicative of awareness and responsibility, while the majority adhered to mild exercise levels and showed either a minor increase in weight or no change confirming evidence from previous studies. $[12,13,14]$.

\section{Overall Diet}

These patterns are a matter of concern for the nation as a whole as an unhealthy diet positions people at a greater risk of infection to viruses like COVID-19, diseases like diabetes, cardiac complications and more. $[15,16,17]$. While only $30 \%$ agreed that their diet was healthier in lockdown, around 52.70 reported less healthy dietary patterns. It was interesting to observe that in very few cases participants adhered to a less healthy diet and still managed to lose weight. These participants managed to keep the weight the same or reduce it by an intense exercise routine.

\section{Conclusion}

The survey examined the participants on various variables including water and food intake, meal frequency, weight changes and level of exercise. The responses of 110 young adults (16-25) were recorded and analysed. Charts of the data were made and interpreted. It was observed that the lockdown harmed the dietary habits of young adults in the capital city of India. Lockdown has caused a change in mostly all key variables and variables like workout levels, weight changes and meal frequency were most severely impacted. Due to a lack of available infrastructure as gyms and parks were closed the level of exercise fell hugely. The lockdown also impacted the stability of weight as the daily calorie intake was not matched by the daily calories burned. Incessant eating between meals also increased as shown by the large increase in processed food consumption. The effect of a lack of exercise and increased processed food intake is shown by the huge percentage of participants reporting an increase in weight. Protein intake was also reduced on average as protein foods fell more (due to the fall in meat and non-veg foods) even though some protein foods like legumes and dairy had increased consumption. The lack of physical exercises also impacted the water intake of young adults as a high majority report themselves to be taking less than the recommended amount of water (78\%). 
However one positive outcome of increased fresh fruits and vegetable consumption should also be taken into consideration. The overall level of health has fallen due to poor dietary habits because of the lockdown. This result coincides with participants' perception as the majority of respondents believe that they are less healthy overall during the lockdown.

\section{What this study adds to existing knowledge}

Existing literature includes research done in regions of Europe, South America and full India. Regionspecific research is absent concerning Delhi- NCR. The study is specific to age groups as well. Existing literature is diversified concerning age groups. This study is unique as it analyses the dietary habits of youngsters of a particular age group i.e. 16-27 years.

\section{Acknowledgements}

The authors express their gratitude towards Ms Prachita Arora (PhD Candidate at Birbal Sahni Institute of Palaeosciences) and Ms Rashika Sethi (Investment Banking Associate at Startup Angels Network) for their indispensable guidance.

\section{Author contribution}

Devesh Arora: Designing work plan, writing the article and data presentation. Shaurya Narang: Writing the article, survey design, data collection and proofreading

\section{Reference}

01. Ministry of Health and Family Welfare. Government of India. May 15, 2021. Available at: [Article] [Crossref][PubMed][Google Scholar]

02. Rehman $U$, Shahnawaz MG, Khan $\mathbf{N H}$, Kharshiing KD, Khursheed $M$, Gupta $K$, et al. Depression, Anxiety and Stress Among Indians in Times of Covid-19 Lockdown. Community Ment Health J. 2021 Jan;57(1)42-48. doi: 10.1007/s1059 7-020-00664-x [Crossref][PubMed][Google Scholar]

03. O'Neil A, Quirk SE, Housden S, Brennan SL, Williams LJ, Pasco JA, et al. Relationship between diet and mental health in children and adolescentsa systematic review. Am J Public Health. 2014 Oct;104(10)e31-42. doi: 10.2105/AJPH.2014. 302110 [Crossref][PubMed][Google Scholar]
04. Hooper LV. You AhR what you eat- linking diet and immunity. Cell. 2011 Oct 28;147(3)489-91. doi: 10.1016/j.cell.2011.10.004 [Crossref][PubMed] [Google Scholar]

05. /Kumar R, Arumugham Dhanaraj S, Saini R, Kumari P, Roy P, Paul S. Impacts on dietary habits and health of Indian population during COVID-19 lockdown. Public Health Rev Int J Public Health Res. 2020;7(6)38-50.

[Crossref][PubMed][Google Scholar]

06. Scarmozzino F, Visioli F. Covid-19 and the Subsequent Lockdown Modified Dietary Habits of Almost Half the Population in an Italian Sample. Foods. 2020 May 25;9(5)675. doi: 10.3390/foods9050675 [Crossref][PubMed][Google Scholar]

07. Bennett G, Young E, Butler I, Coe S. The Impact of Lockdown During the COVID-19 Outbreak on Dietary Habits in Various Population Groups- A Scoping Review. Front Nutr. 2021 Mar 4;8;626432. doi: 10.3389/fnut.2021.626432 [Crossref][PubMed] [Google Scholar]

08. Armstrong LE, Johnson EC. Water Intake, Water Balance, and the Elusive Daily Water Requirement. Nutrients. 2018 Dec 5;10(12)1928. doi: 10.3390/nu10121928 [Crossref][PubMed][Google Scholar]

09. Popkin BM, D'Anci KE, Rosenberg IH. Water, hydration, and health. Nutr Rev. 2010 Aug;68(8)439-58. doi: 10.1111/j.1753-4887.2010. 00304.x [Crossref][PubMed][Google Scholar]

10. Arora M, Nazar GP, Gupta VK, Perry CL, Reddy $\mathrm{KS}$, Stigler $\mathrm{MH}$. Association of breakfast intake with obesity, dietary and physical activity behavior among urban school-aged adolescents in Delhi, India- results of a cross-sectional study. BMC Public Health. 2012 Oct 17;12;881. doi: 10.1186/14712458-12-881 [Crossref][PubMed][Google Scholar]

11. Lim MA, Pranata R. The Danger of Sedentary Lifestyle in Diabetic and Obese People During the COVID-19 Pandemic. Clin Med Insights Endocrinol Diabetes. 2020 Oct 19;13;1179551420964487. doi: 10.1177/1179551420964487 [Crossref][PubMed] [Google Scholar]

12. Blair SN. Evidence for success of exercise in weight loss and control. Ann Intern Med. 1993 Oct 1;119(7 Pt 2)702-6. doi: 10.7326/0003-4819-1197_part_2-199310011-00015 [Crossref][PubMed] [Google Scholar] 
13. Hussain A, Mahawar K, Xia Z, Yang W, El-Hasani S. Obesity and mortality of COVID-19. Metaanalysis. Obes Res Clin Pract. 2020 JulAug;14(4)295-300. 10.1016/j.orcp.2020.07.002 [Crossref][PubMed] [Google Scholar]

14. Gao F, Zheng KI, Wang XB, Sun QF, Pan KH, Wang TY, et al. Obesity Is a Risk Factor for Greater COVID-19 Severity. Diabetes Care. 2020 Jul;43(7)e72-e74. doi: 10.2337/dc20-0682 [Crossref][PubMed][Google Scholar]

15. Butler MJ, Barrientos RM. The impact of nutrition on COVID-19 susceptibility and long-term consequences. Brain Behav Immun. 2020 Jul;87;53-54. doi: 10.1016/j.bbi.2020.04.040 [Crossref][PubMed][Google Scholar]
16. Zhang, Jian, and Dong Li. "Contribution of Hyperglycemia and Unhealthy Diet to Cardiovascular Mortality". Obesity and Diabetes, Springer, Cham. 2020;471-477. [Crossref][PubMed][Google Scholar] 17. Hu FB. Globalization of diabetes- the role of diet, lifestyle, and genes. Diabetes Care. 2011 Jun;34(6)1249-57. doi: 10.2337/dc11-0442 [Crossref][PubMed][Google Scholar] 